Full length article

\title{
Effect of heat treatment on the blast loading response of combined geometry shell core sandwich structures
}

\author{
Alper Tasdemirci *, Ali Kara, Kivanc Turan, Selim Sahin, Mustafa Guden \\ Dynamic Testing and Modeling Laboratory and Department of Mechanical Engineering, Izmir Institute of Technology, Gulbahce, Urla, Izmir, Turkey
}

\section{A R T I C L E I N F O}

\section{Article history:}

Received 3 June 2015

Received in revised form

11 December 2015

Accepted 11 December 2015

Available online 22 December 2015

\section{Keywords:}

Sandwich structures with combined geo-

metry shell cores

Heat treatment

Energy Absorption

Blast loading

CONWEP

Finite Element Method

\begin{abstract}
A B S T R A C T
The effect of heat treatment on the dynamic crushing and energy absorption behavior of combined geometry shell cores (hemisphere and cylinder) of sandwich structures were investigated both experimentally and numerically. The applied heat treatment on the combined geometry shell cores relieved the stress caused by deep drawing, diminishing the peak transmitted forces. The verified numerical models of the as-received and heat-treated combined geometry shells were used to model blast loading of various sandwich configurations and the additional sandwich configurations of reversing the cylindrical side of the cores to the impacted side. Both the applied heat-treatment and the reversing process decreased the magnitude of the force transmitted to the protected structure. The applied heat treatment increased the arrival time of blast force wave to the protected structure, while the reversing resulted in opposite.
\end{abstract}

(c) 2015 Elsevier Ltd. All rights reserved.

\section{Introduction}

Energy absorbing structures are widely used in vehicle crashworthiness, highway safety, sacrificial claddings and armor protections. These are mostly the thin-walled structures of cylindrical, square and hexagonal tubes, cones and spheres with comparable high strength/weight ratios. The energy absorption characteristics of these structures can be tailored with the various combinations of simple geometries such as cylindrical, spherical and conical shapes, which have already been employed in aerospace, automotive and marine industries. The superior energy absorption characteristics of combined geometry shells lie in the deformation and collapse behavior of their constituents.

Gupta et al. [1] analyzed the collapse behavior of a combined geometry shell of a frusta and a hemispherical cap. The global deformation of the shell was progressive and the deformation mode of conical frusta part was found to be different from that of the geometry without a cap [2]. Niknejad and Tavassolimanesh [3] investigated the inversion process of an end-capped frusta. The end-capped frusta were treated as a special case of combined geometry. Gupta [4] studied the axial crushing of a metallic frusta with varying wall thicknesses, treated as the combinations of constant wall thickness frusta of infinite number. Gupta [5] and Gupta and Gupta [6] investigated the axial collapse of behavior of the combined tube-cone geometry. The collapse behavior changed

\footnotetext{
* Corresponding author.
}

with the dimensions of conical portion and the deformation mode and the region of fold formation changed with the thickness. Ghamarian and Abadi [7], Ghamarian et al. [8] and Ghamarian and Zarei [9] investigated the energy absorption characteristics of empty and foam-filled circular and conical end-capped tubes and showed that the absorbed energy increased with increasing impact velocity. Ghamarian et al. [10] showed that the crush force efficiency and absorbed energy of shallow spheres as end-cap in conical tubes increased with increasing spherical cap radius. Shojaeefard et al. [11] showed that the absorbed energy of combined tubes were higher than those of individual components of the same length. Shahi and Marzbanrad [12] investigated the crushing behavior of segmented thin walled tubes. Sahu and Gupta [13] studied the large deformation of a combined geometry consisting of three individual geometries, namely an end-capped cylinder, a frusta, and a spherical crater. The increase in the thickness of shell resulted in higher buckling loads and changed the location of fold initiation and the fold thicknesses varied with the friction coefficient. Gupta and Gupta [14] and Gupta [15] investigated the effect of heat treatment and size of cutouts on the collapse behavior of aluminum and mild steel thin walled tubes. Annealing caused the change the deformation mode of aluminum tubes from diamond to ring and steel tubes from concertina to diamond mode. Gupta and Gupta [16] investigated the collapse of metallic hemispherical shells compressed with hemispherical nose indenter and showed that specimens tested in as-received condition absorbed more energy than the annealed condition, resulting from reduced yield strength after annealing. No noticeable change was 
a

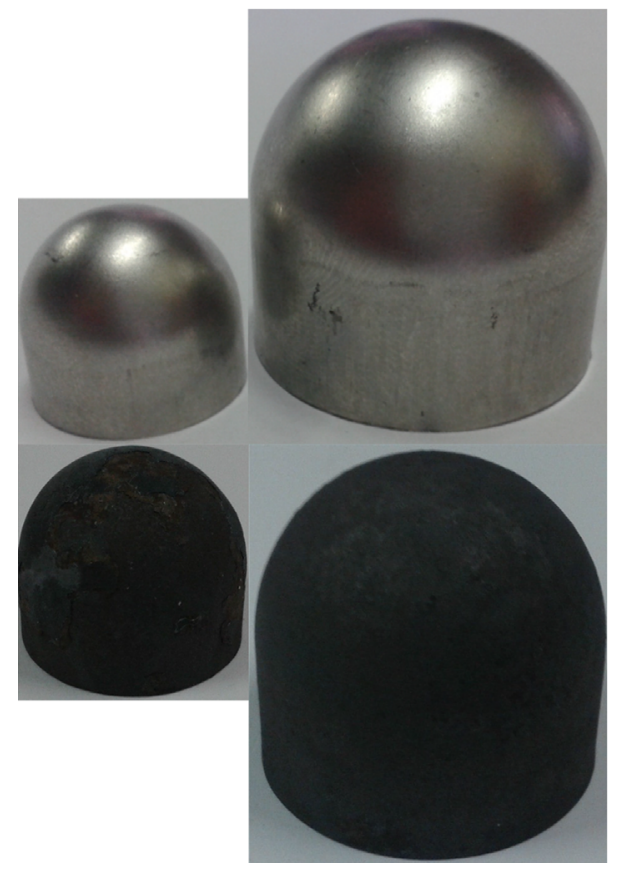

b

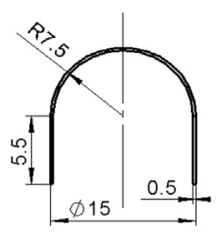

S1XX

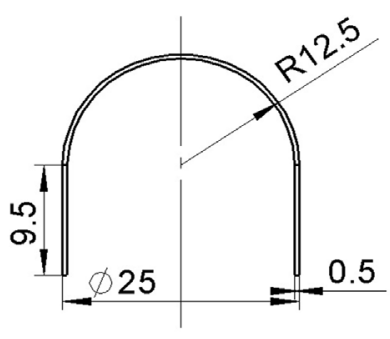

B1XX

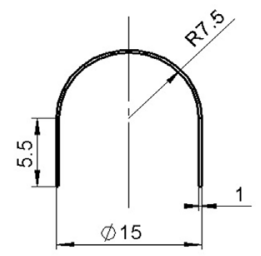

S2XX

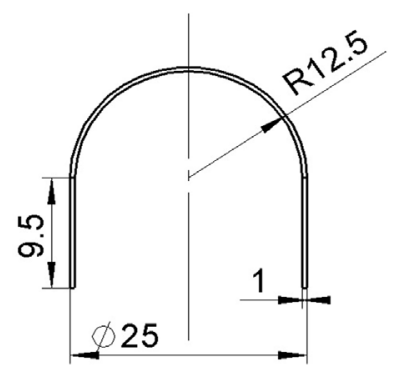

B2XX

Fig. 1. (a) As received and heat-treated combined geometry shells and (b) the geometrical parameters.

observed in the collapse mode as lower amount of plastic deformation was induced during the spinning process.

Various types of sandwiches with different core materials and topology have also been designed and suggested, including metallic foams $[17,18]$, metallic honeycombs [19-21], and corrugated structures [22,23]. Alberdi et al. [24] evaluated the performance of sandwich structures against blast using CONWEP functions [25] incorporated in LS-DYNA [26]. The folded core topologies exhibited superior blast performance than honeycomb topologies considering their lower back plate deflections, lower transmitted forces to the back plate, and higher energy dissipation. Palanivelu et al. investigated recycled beverage cans for low velocity impact applications [27] and the use of their arrangements for a macro foam as sacrificial cladding [28] against blast loading.

The aim of the current study is to determine the effect of heat treatment on the crushing behavior and energy absorption characteristics of the combined geometry shells (hemispherical cap and cylindrical segment) at quasi-static and high strain rates. The quasi-static and dynamic deformation behavior of the tested as received combined geometry shells and their sandwiches were recently investigated in Refs. [29] and [30] by the same authors. Previous results revealed that failure/fracture of few specimens occurred during crushing, imparting the energy dissipating capability. Therefore, heat treatment was presented in this study as a stress relieving procedure to induce more ductile material behavior in order to increase absorbed energy without failure/fracture. Current study also utilized numerical approach in order to determine dynamic crushing behavior of sandwiches with cores of as-received and heat-treated combined geometries and their configurations under blast loading conditions.

\section{Manufacturing of combined geometry shells and heat treatment}

The investigated combined geometry shells were formed by deep-drawing 0.5 and $1 \mathrm{~mm}$ thick AISI 304L stainless steel sheet blanks. The tooling for the deep-drawing process was machined locally for the current study. The edge of the deep drawn cylindrical segment on the bottom side formed during the forming process was trimmed by a cutting tool on a CNC lathe. The prepared specimens of various configurations commonly consisted of a hemispherical cap and a cylindrical segment. Four different combined geometry shell configurations were tested and modeled. The coding of the configurations is as follows: $\mathrm{S} 1 \mathrm{XH}, \mathrm{S} 2 \mathrm{XH}, \mathrm{B} 1 \mathrm{XH}$ and $\mathrm{B} 2 \mathrm{XH}$. The first letters, $\mathrm{S}$ and $\mathrm{B}$, refer to the sample's radius. The samples $15 \mathrm{~mm}$ in diameter are coded as $\mathrm{S}$ (small) and the samples in $25 \mathrm{~mm}$ diameter as B (big). The numbers after the first letters, 1 and 2, refer to the sample thickness of 0.5 and $1 \mathrm{~mm}$, respectively. The last number in the coding, $\mathrm{X}$, represents the type of the test applied. The quasi-static test is coded as 1 and dropweight test as 2 [29]. In this study, the last letter $\mathrm{H}$ was introduced which refers to heat-treatment. The code of $\mathrm{B} 12 \mathrm{H}$, for example, refers to a heat treated sample with $25 \mathrm{~mm}$ diameter and $0.5 \mathrm{~mm}$ thickness, tested in drop-weight. The numerical and measured thickness vs. distance from apex graphs of deep drawn S2X and B2X samples were previously shown in Ref. [29]. The deep drawing process caused slight or no increase in the thickness of the cylindrical segment while the thickness decreased in the hemispherical cap. For example, the hemi-spherical cap thickness reduced to $0.8 \mathrm{~mm}$ on the average after deep drawing, while the thickness of the cylindrical segment remained almost the same for a blank thickness of $1 \mathrm{~mm}$.

The heat treatment process consisted of two steps: annealing at $1100{ }^{\circ} \mathrm{C}$, followed by an immediate air quenching. The optimum heat treatment route was determined by varying the annealing times: $0.5,2.0$, and $4.0 \mathrm{~h}$ and an annealing time of $2 \mathrm{~h}$ was determined to be optimum (no change in mechanical behavior after $2 \mathrm{~h}$ ). The annealing time strongly depends on the amount of plastic deformation induced during deep-drawing. Comparable results were also reported for a similar material by Weber et al. [31]. The pictures of the prepared small and big radius as-received and heat-treated combined shells and the geometrical parameters of the samples tested are shown in Fig. 1a and b. 


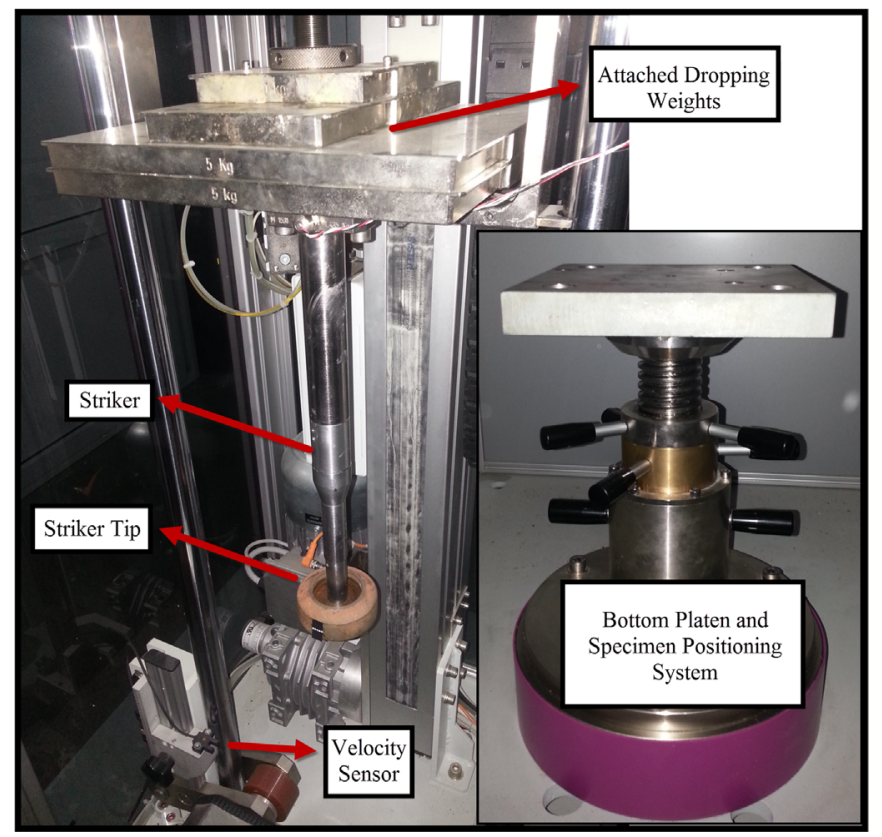

Fig. 2. Fractovis Plus drop weight tester.

\section{Experiments}

\subsection{Quasi-static experimental set-up}

The quasi-static crushing experiments were conducted in a Shimadzu AG-X universal testing machine at the crosshead speeds of 0.78 and $1.38 \mathrm{~mm} \mathrm{~min}^{-1}$ (corresponding to initial nominal strain rate of $1 \times 10^{-3} \mathrm{~s}^{-1}$ ) for the specimen heights of 13 and $23 \mathrm{~mm}$, respectively. The displacement of the test sample was measured using a video extensometer attached to the testing machine and the deformation was recorded using a Photron FastCam high speed camera at a frame rate of $50 \mathrm{fps}$.

\subsection{Drop weight experimental setup}

Low velocity crushing tests were performed in a Fractovis Plus drop weight tester (Fig. 2). The main components of the drop weight tester include striker and its holder, striker weights and tip. The striker was attached to a $90 \mathrm{kN}$ strain-gaged sensor. The striker velocity was measured by the photocells of the dropweight tester and the tests were conducted using a $70 \mathrm{~mm}$ diameter flat end striker tip. The absorbed energy was internally calculated by integrating the force-displacement curves. The striker velocities were 5.1 and $4.6 \mathrm{~m} / \mathrm{s}$ for 13 and $23 \mathrm{~mm}$ long specimens, respectively. The weights were selected based on the energy absorbed in the quasi-static crushing test. The tests were recorded using the high speed camera at a frame rate of $10000 \mathrm{fps}$.

\section{Finite element modeling}

\subsection{Material models and validation}

All models were implemented in LS-DYNA 971 explicit commercial finite element code. Since the crushing modes were not axisymmetric, the shells were modeled in full geometry. The finite element model of the deep-drawing of steel blank shown in Fig. 3a consisted of punch, blank holder, forming die and blank. The blank was modeled using Belytschko-Tsay shell elements with seven integration points through the thickness. The optimum number of elements was selected based on a mesh sensitivity analysis. The analysis showed that an element size of $0.5 \mathrm{~mm}$ converged the solutions within a reasonable time. In the simulations, the displacement control curve with a trapezoidal velocity profile was used as input. Since, the displacement rates were relatively low for an explicit solver, the mass-scaling [32] was applied to obtain reasonably small time steps and to decrease the solution time. The density of blank material was scaled down by a factor of 1000 and the tool (punch) velocity was set at $10 \mathrm{~m} \mathrm{~s}^{-1}$. With the massscaling, the kinetic energy to total internal energy ratio was less than $4 \%$ over the period of deep drawing process, ensuring a quasistatic strain rate. Contact one way forming surface to surface definition was used to account for the contact between the tooling and blank material. Between all surfaces in-contact, a static friction coefficient of 0.15 and a dynamic friction coefficient of 0.1 were assumed in the numerical model. The deep-drawn combined geometry shells retain significant amount of residual strain. LS-DYNA 971 allows users to perform follow-on simulations such as trimming and additional forming/crushing. For this purpose, the "dynain" file generation methodology [26,29,33] was followed. This dynain file included into a new LS-DYNA 971 input deck for quasi-static and dynamic crushing simulations with asreceived shells. In order to model heat-treated material behavior,

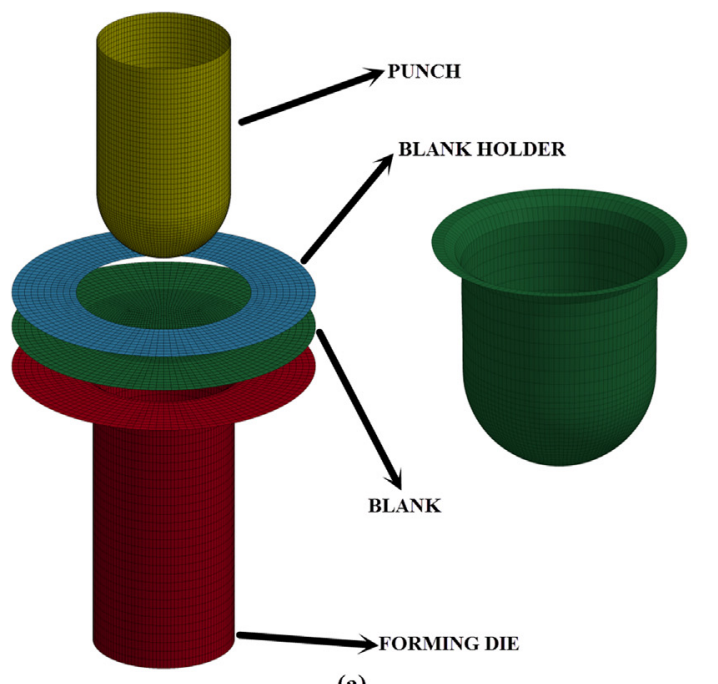

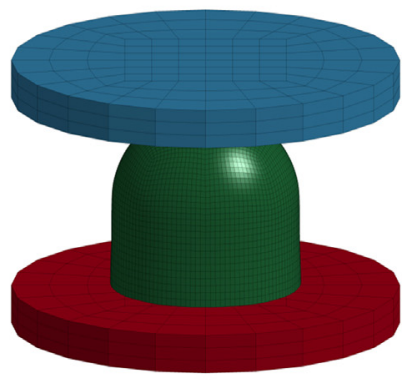

(b)

(a)

Fig. 3. Model of (a) deep drawing process and (b) the quasi-static and dynamic compression of the combined shell. 
initial stress and strain histories generated in the previous deepdrawing simulations were intentionally removed.

In the simulations, die, punch and blank holder were modeled rigid and the blank deformation was modeled using the JohnsonCook $(\mathrm{J}-\mathrm{C})$ material model. In this material model, the equivalent $\operatorname{stress}\left(\sigma_{e q}\right)$ is expressed as

$\sigma_{e q}=\left(A+B \varepsilon_{e q}{ }^{n}\right)\left(1+C \ln \left(\dot{\varepsilon}_{e q}^{*}\right)\right)\left(1-T^{* m}\right)$

where, $\varepsilon_{\text {eq }}$ is the equivalent plastic strain and $A, B, n, C$ and $m$ are the material constants. The dimensionless plastic strain rate $\left(\dot{\varepsilon}_{e q}^{*}\right)$ is given by $\dot{\varepsilon}_{e q}^{*}=\frac{\dot{\varepsilon}_{e q}}{\dot{\varepsilon}_{0}}$, where $\dot{\varepsilon}_{0}$ is a user defined reference strain rate, and $\left(\dot{\varepsilon}_{e q}\right)$ is the equivalent plastic strain rate. The homologous temperature $\left(T^{*}\right)$ is defined as $T^{*}=\frac{\left(T-T_{r}\right)}{\left(T_{m}-T_{r}\right)}$, where $T$ is the absolute temperature, $T_{r}$ is the room temperature and $T_{m}$ is the melting temperature.

The failure model considered in this study is based on JohnsonCook damage model. The Johnson-Cook damage model fracture strain $\left(\varepsilon_{f}\right)$ is,

$\varepsilon_{f}=\left[D_{1}+D_{2} e^{D_{3} \sigma^{*}}\right]\left[1+D_{4} \ln \left(\frac{\dot{\varepsilon}}{\dot{\varepsilon}_{0}}\right)\right]\left(1+D_{5} T^{*}\right)$

where $D_{1}, D_{2}, D_{3}, D_{4}$ and $D_{5}$ are damage parameters, $\sigma^{*}=\sigma_{m} / \sigma_{e}$ is stress triaxiality ratio; where $\sigma_{m}$ is the mean stress and $\sigma_{e}$ is the equivalent stress. In the current study, the stress state does not vary significantly during compression. Thus, the following simplified form concentrating only on the strain rate dependency was considered

$\varepsilon_{f}=D_{1}\left[1+D_{4} \ln \left(\frac{\dot{\varepsilon}}{\dot{\varepsilon}_{0}}\right)\right]$

Note also that, thermal effects on both material and damage models were neglected. The determined J-C material model constants of as-received and heat-treated AISI $304 \mathrm{~L}$ stainless steel are tabulated in Table 1 . The stress model constants for heat treated samples in Table 1 were obtained from the stress-strain curves of the heat treated tension test specimens (not shown here), while the stress and damage model constants for as-received samples were taken from Ref. [29]. Note that the damage model of the heat-treated material was kept the same as that of the as-received material.

The finite element model of the quasi-static and dynamic compression of the combined geometry shell is shown in Fig. 3b and consisted of a moving rigid upper plate, specimen and stationery rigid lower plate. In the quasi-static simulations, the upper plate moved with the cross-head velocity along the $z$-axis while the lower plate was fully constrained in all directions. In the dropweight simulations, the top rigid plate moved on its axis with a downward velocity by the fall of dropping weight and node based mass lumping methodology was followed in order to match the total weight of the drop-weight tester cross-head. Two different types of contact were used in the numerical model. For the combined geometry shell itself, an eroding single surface contact was used to account for the contact between folds during the deformation and new contact interfaces created due to the erosion, if there was any. While an eroding surface to surface contact was applied between the combined geometry and rigid top/bottom

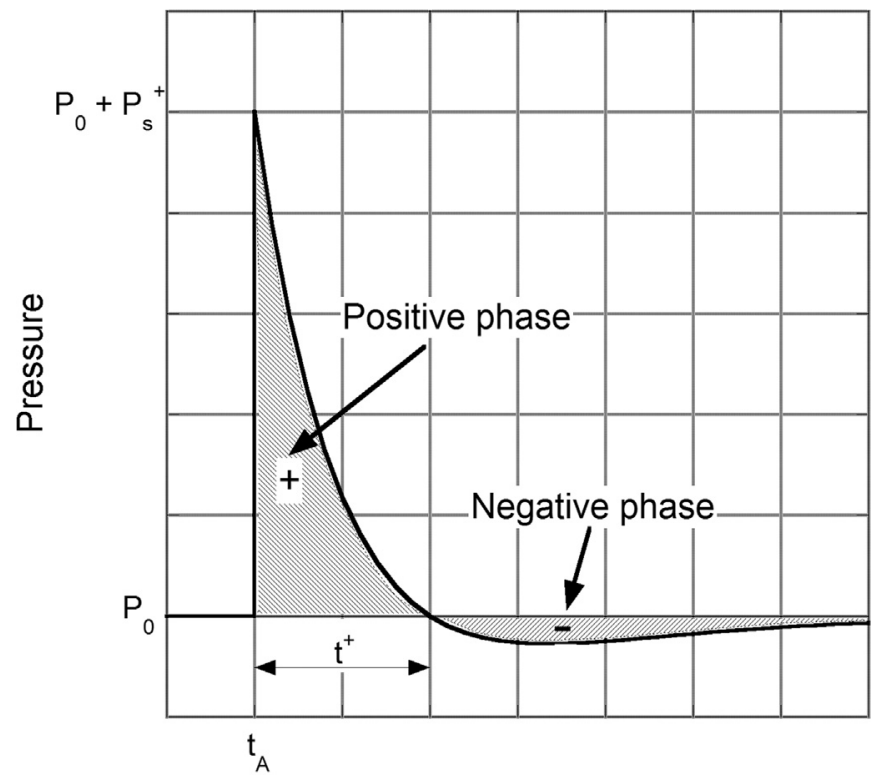

Time

Fig. 4. Blast wave pressure-time profile.

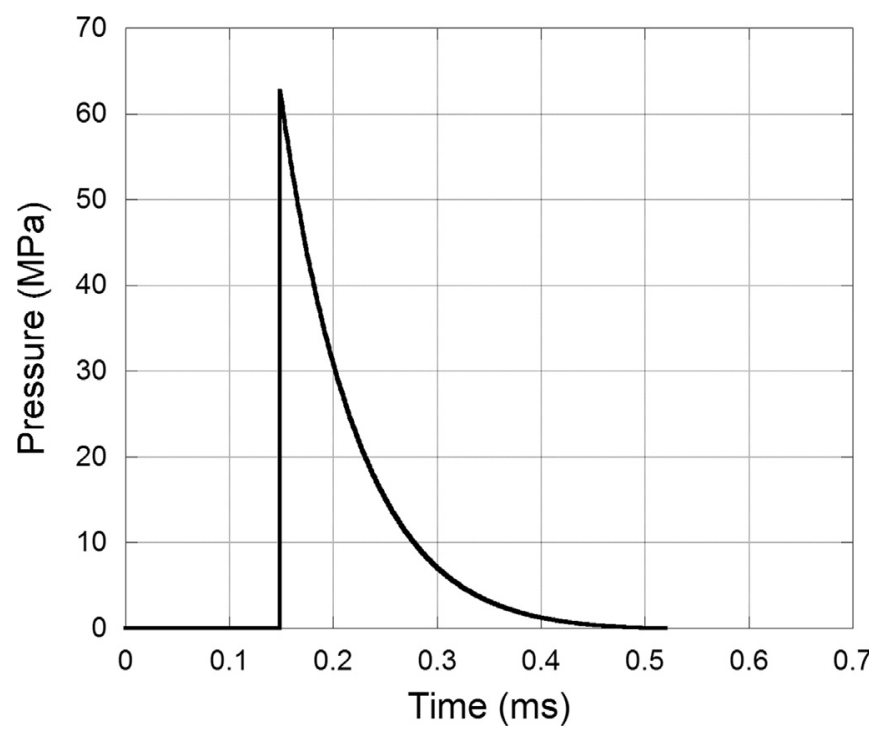

Fig. 5. Blast wave pressure-time profile for a $5 \mathrm{~kg}$ of TNT equivalent mass with a standoff distance of $600 \mathrm{~mm}$.

plates. A static friction coefficient of 0.3 and a dynamic friction coefficient of 0.2 between the contact surfaces were assumed in the numerical study.

\subsection{Blast modeling}

Once the numerical model was verified then the numerical study was extended to investigate the dynamic response of sandwich structures consisting of combined geometry shell cores

Table 1

Johnson-Cook model properties of as-received and heat-treated AISI 304L stainless steel used in numerical models.

\begin{tabular}{|c|c|c|c|c|c|c|c|}
\hline$\rho\left(\mathrm{kg} / \mathrm{m}^{3}\right)$ & $G(\mathbf{G P a})$ & $E(\mathbf{G P a})$ & $v$ & $A(\mathrm{MPa})$ & B (MPa) & $n$ & $C$ \\
\hline 7830 & 80 & 193 & 0.305 & 264 & 1567.33 & 0.703 & 0.067 \\
\hline D1 & D4 & $A_{H T}$ (MPa) & $B_{H T}$ (MPa) & $n_{H T}$ & & & \\
\hline 0.53467 & -0.01913 & 232 & 1272.6 & 0.8288 & & & \\
\hline
\end{tabular}


a

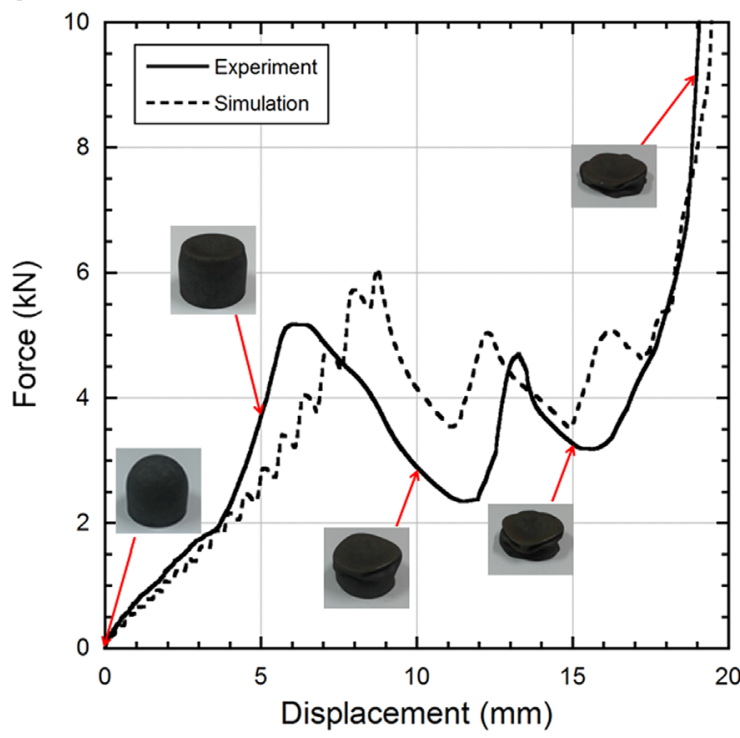

C

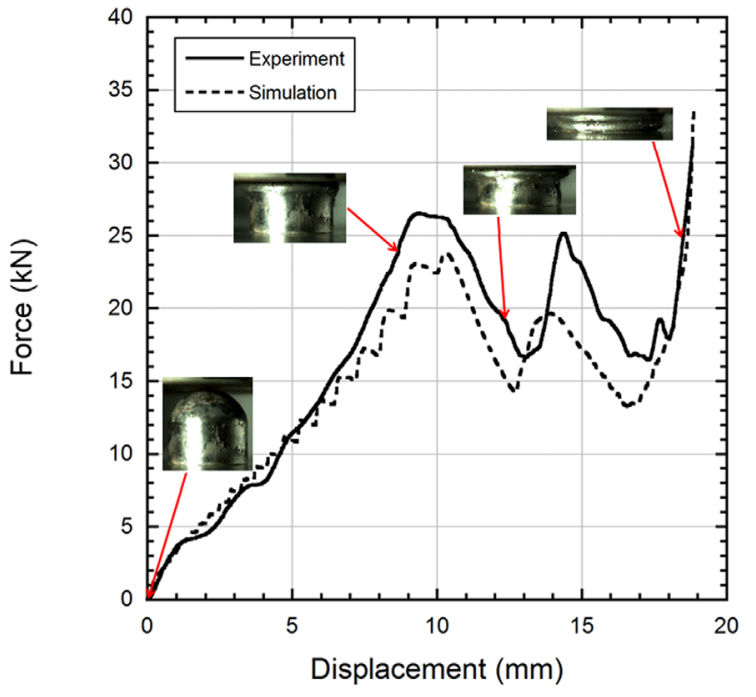

b

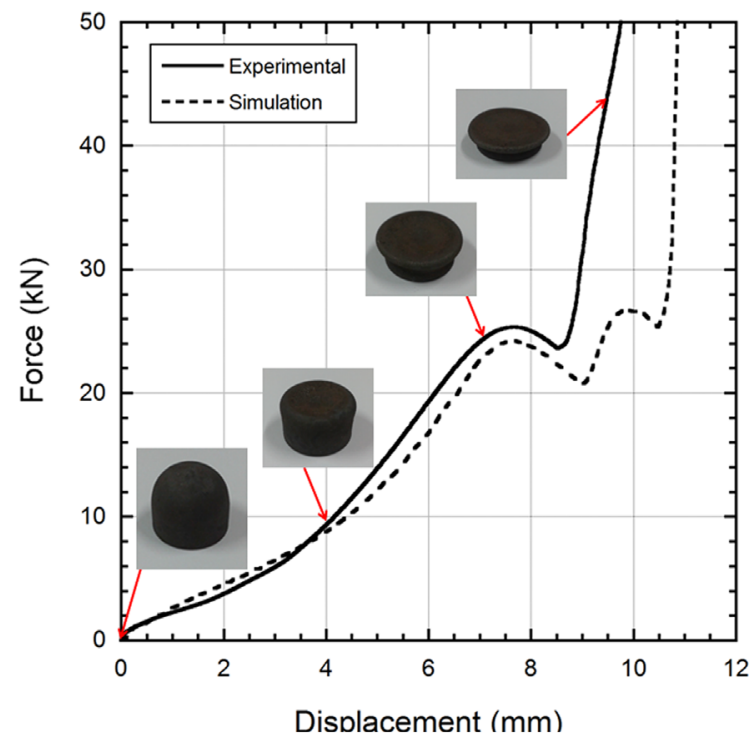

d

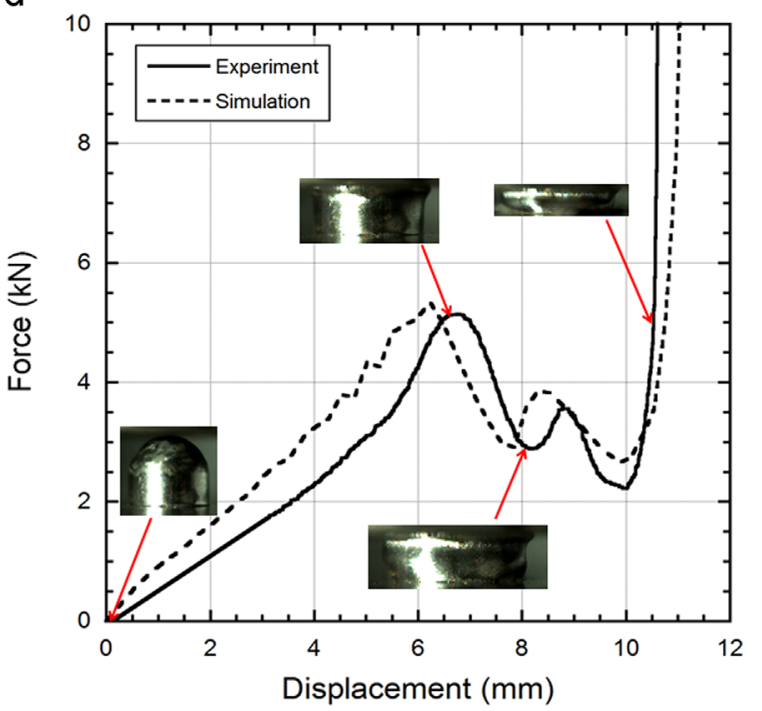

Fig. 6. Experimental and numerical force-displacement curves of (a) $\mathrm{B} 11 \mathrm{H}$, (b) $\mathrm{S} 21 \mathrm{H},(\mathrm{c}) \mathrm{B} 22 \mathrm{H}$, and (d) $\mathrm{S} 12 \mathrm{H}$.

against blast loading. An explosion is a rapid release of energy in an extreme manner leading to a blast wave which is the most destructive component of an explosion. Magnitude of blast load can be represented as a function of scaled distance $Z[34]$ as,

$Z=R / W^{1 / 3}$

where, $R$ is the distance from the explosive and $W$ is the weight of charge in terms of TNT equivalent. The pressure resulting from a blast wave for a scaled distance is shown in Fig. 4. For a given scaled distance, the pressure resulting from the blast wave can be modeled using the Friedlander equation [34] as,

$P(t)=P_{s}^{+}\left(1-\frac{t}{t^{+}}\right) e^{-b \frac{t}{t^{+}}}$

where, $P_{S}{ }^{+}$is the peak incident pressure, $t$ is the time, $t^{+}$is the positive phase duration, $b$ is the decay parameter, $t_{A}$ is the time of arrival.

In LS-DYNA, air blast loading on structures can be modeled using CONWEP function [25] and this method was used in the current study to model the pressure load on the front face sheet of the combined geometry core sandwiches. CONWEP function is

$P(\tau)=P_{r}^{*} \cos ^{2} \theta+P_{\text {inc }} *\left(1+\cos ^{2} \theta-2 * \cos \theta\right)$

where, $\theta$ is the incidence angle, $P_{\text {inc }}$ incident pressure and $P_{r}$ reflected pressure [35].

In order to account for the application of pressure load from the detonation of conventional explosive, an air blast function can be defined in LS-DYNA 971 using *LOAD_BLAST_ENHANCED card which may also include enhancements for treating ground-reflected waves, moving warheads and multiple blast sources.

In the current investigation, a $5 \mathrm{~kg}$ of TNT equivalent mass was defined with a standoff distance of $600 \mathrm{~mm}$. The blast source was a spherical air burst and the negative phase was ignored in CONWEP definition. Detonation starts immediately at the beginning of simulations with an arrival time of $150 \mu \mathrm{s}$ and a total peak pressure of $62 \mathrm{MPa}$ as seen in Fig. 5.

The blast protection performance of the proposed sandwich structures (supported by stainless steel witness plates of thickness of $20 \mathrm{~mm}$ ) was determined with comparing transmitted force and absorbed energy values between sixteen sandwich structures. The 
a
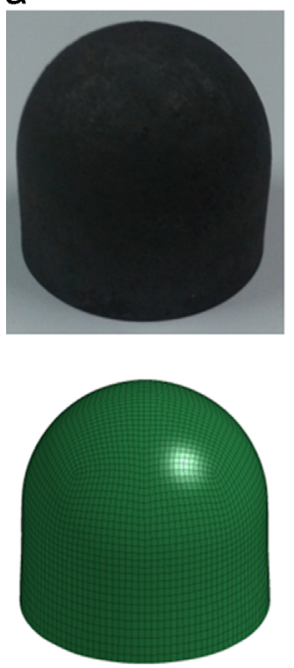

$0 \mathrm{~mm}$

b
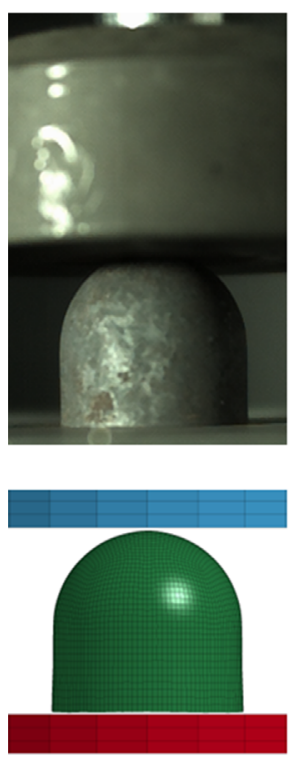

$0 \mathrm{~mm}$
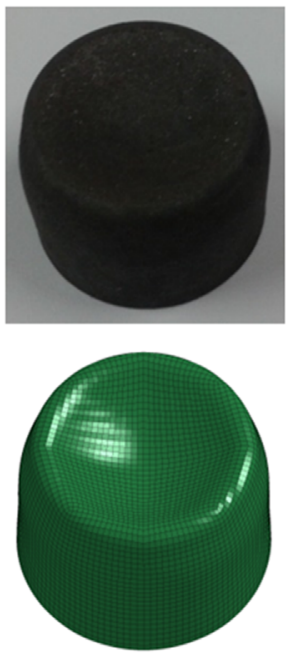

$5 \mathrm{~mm}$
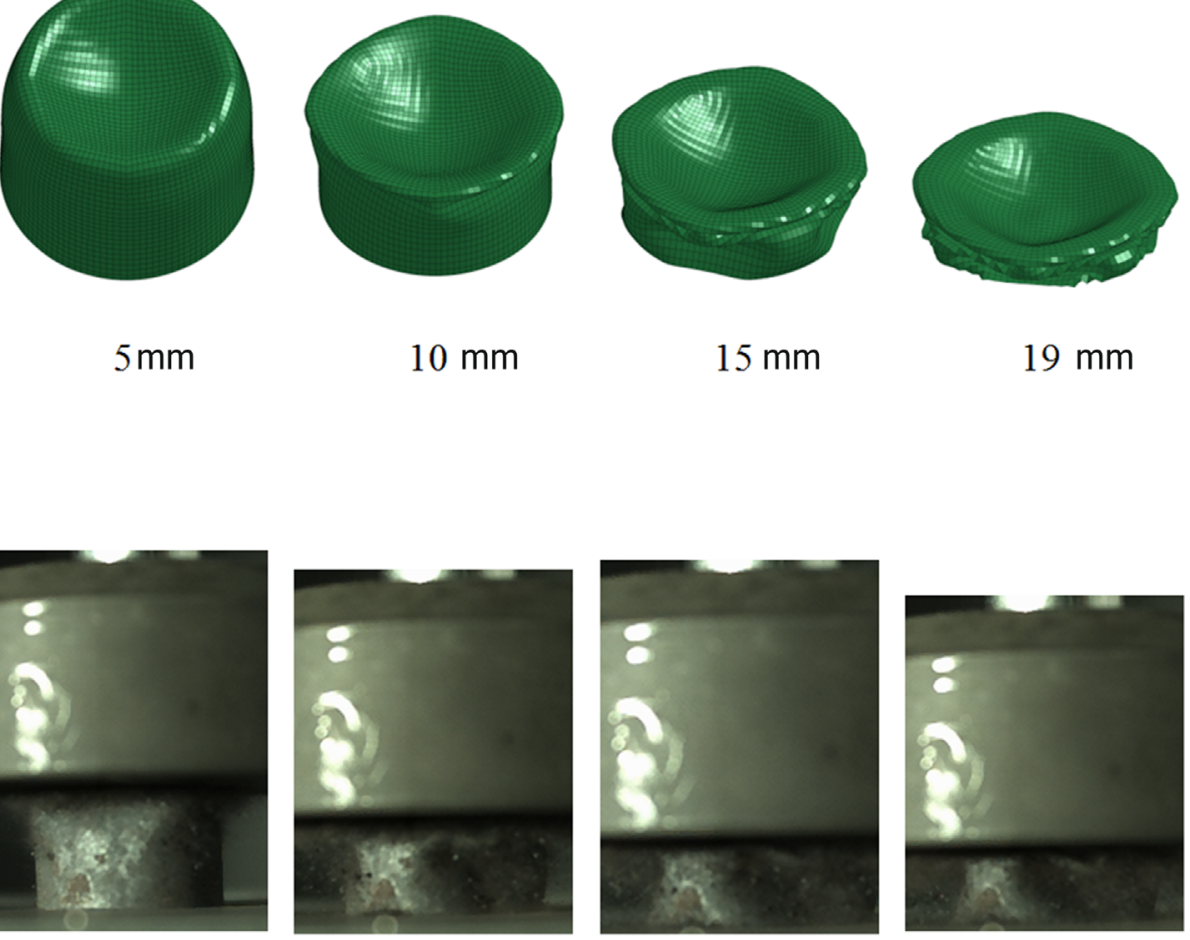

$10 \mathrm{~mm}$

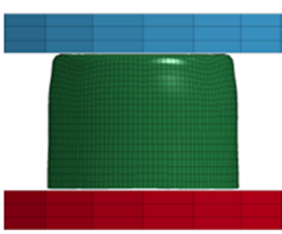

$6.25 \mathrm{~mm}$
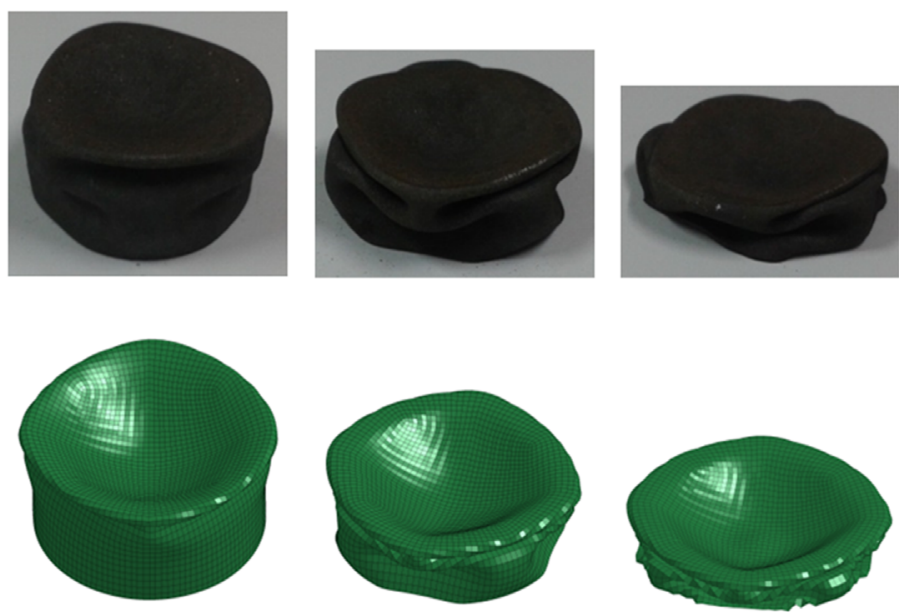

$15 \mathrm{~mm}$

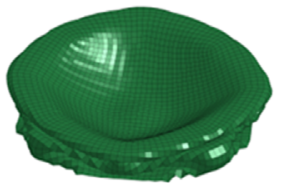

$19 \mathrm{~mm}$

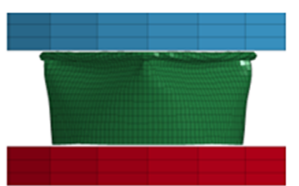

$11.6 \mathrm{~mm}$

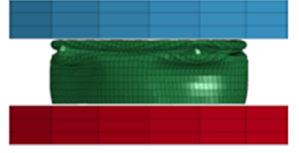

$15.2 \mathrm{~mm}$

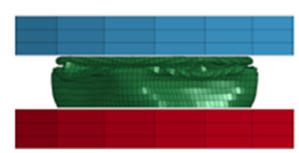

$16.9 \mathrm{~mm}$

Fig. 7. Experimental and numerically deformed pictures of (a) $\mathrm{B} 11 \mathrm{H}$ and (b) $\mathrm{B} 12 \mathrm{H}$.

coding of sandwiches is as follows: B1AF is a sandwich consisting $25 \mathrm{~mm}$ diameter and $0.5 \mathrm{~mm}$ thickness specimens in as-received condition (A) with spherical part at the impacting side (F), S2HR is a sandwich consisting $15 \mathrm{~mm}$ diameter and $1.0 \mathrm{~mm}$ thickness specimens in heat-treated condition $(\mathrm{H})$ with cylindrical part at the impacting side $(R)$.

\section{Results and discussions}

5.1. Experimental and numerical crushing of heat-treated combined geometry shells

The quasi-static and dynamic experimental and numerical loaddeformation curves of $\mathrm{B} 11 \mathrm{H}, \mathrm{S} 21 \mathrm{H}, \mathrm{B} 22 \mathrm{H}$, and $\mathrm{S} 12 \mathrm{H}$ specimens are shown in Fig. 6a-d, respectively. The load-displacement curves follow the progressive buckling after an initial peak force, except S2 specimen (Fig. 6b). The initial deformation is the flattening of apex, followed by the asymmetric folding of cylindrical portion as shown in Fig. 7a and b. Comparing the peak force values of B11 (19.6 kN from Ref. [29]) and B11H (5.2 kN) specimens, a substantial decrease is apparent as a result of heat treatment. It was previously reported that quasi-statically compressed B22 specimen fractured during the test and that ended the buckling of the specimen due to the excessive plastic strain resulted from manufacturing [29]. Heat treatment caused significant amount of reduction in the residual stress and strain levels occurred during manufacturing and fracture did not occur and higher amount of compression stroke was attained successfully in B22H specimen (Fig. 6c). B11H (Fig. 6a) and S21H (Fig. 6d) specimen simulation results show slight differences from 
Table 2

Experimental and numerical crushing results of heat-treated specimens.

\begin{tabular}{|c|c|c|c|c|c|c|c|c|}
\hline Specimen & Drop mass (kg) & Result & $P_{i}(\mathbf{k N})$ & $P_{\max }(\mathbf{k N})$ & $P_{m}(\mathbf{k N})$ & Energy $(\mathrm{J})$ & $S A E(\mathbf{k J} / \mathbf{k g})$ & Compression (mm) \\
\hline \multirow[t]{2}{*}{$\mathrm{S} 11 \mathrm{H}$} & - & Exp. & 4.7 & 4.7 & 2.695 & 27.3 & 13.65 & 10.13 \\
\hline & & Num. & 4.35 & 4.35 & 2.803 & 28.31 & 14.155 & 10.099 \\
\hline \multirow[t]{2}{*}{$\mathrm{S} 12 \mathrm{H}$} & 10.4 & Exp. & 5.22 & 5.22 & 2.6 & 33.35 & 16.675 & 12.82 \\
\hline & & Num. & 5.3 & 5.3 & 3.16 & 32.1 & 16.05 & 10.16 \\
\hline \multirow[t]{2}{*}{$\mathrm{S} 21 \mathrm{H}$} & - & Exp. & 25.2 & 25.2 & 15.58 & 119 & 40 & 7.64 \\
\hline & & Num. & 24.3 & 26.6 & 14.201 & 153.74 & 51.25 & 10.82 \\
\hline \multirow[t]{2}{*}{$\mathrm{S} 22 \mathrm{H}$} & 23.4 & Exp. & 24 & 33.6 & 15.75 & 173.82 & 57.94 & 11.036 \\
\hline & & Num. & 20.63 & 20.63 & 18.73 & 209.86 & 69.95 & 11.204 \\
\hline \multirow[t]{2}{*}{ B11H } & - & Exp. & 5.2 & 5.2 & 3.3 & 61 & 10.16 & 18.48 \\
\hline & & Num. & 6 & 6 & 3.395 & 65.53 & 10.92 & 19.301 \\
\hline \multirow[t]{2}{*}{$\mathrm{B} 12 \mathrm{H}$} & 7.4 & Exp. & 6.4 & 6.4 & 4.1 & 69.06 & 11.51 & 16.84 \\
\hline & & Num. & 6.47 & 6.47 & 4.115 & 66.65 & 11.11 & 16.19 \\
\hline \multirow[t]{2}{*}{$\mathrm{B} 21 \mathrm{H}$} & - & Exp. & 22.8 & 22.8 & 15.6 & 258.8 & 21.6 & 16.59 \\
\hline & & Num. & 22.77 & 22.77 & 14.8 & 282.46 & 23.54 & 19.085 \\
\hline \multirow[t]{2}{*}{$\mathrm{B} 22 \mathrm{H}$} & 14.4 & Exp. & 26.54 & 26.54 & 20.56 & 348.93 & 29.077 & 16.97 \\
\hline & & Num. & 23.86 & 23.86 & 16.19 & 275.41 & 22.95 & 17.011 \\
\hline
\end{tabular}

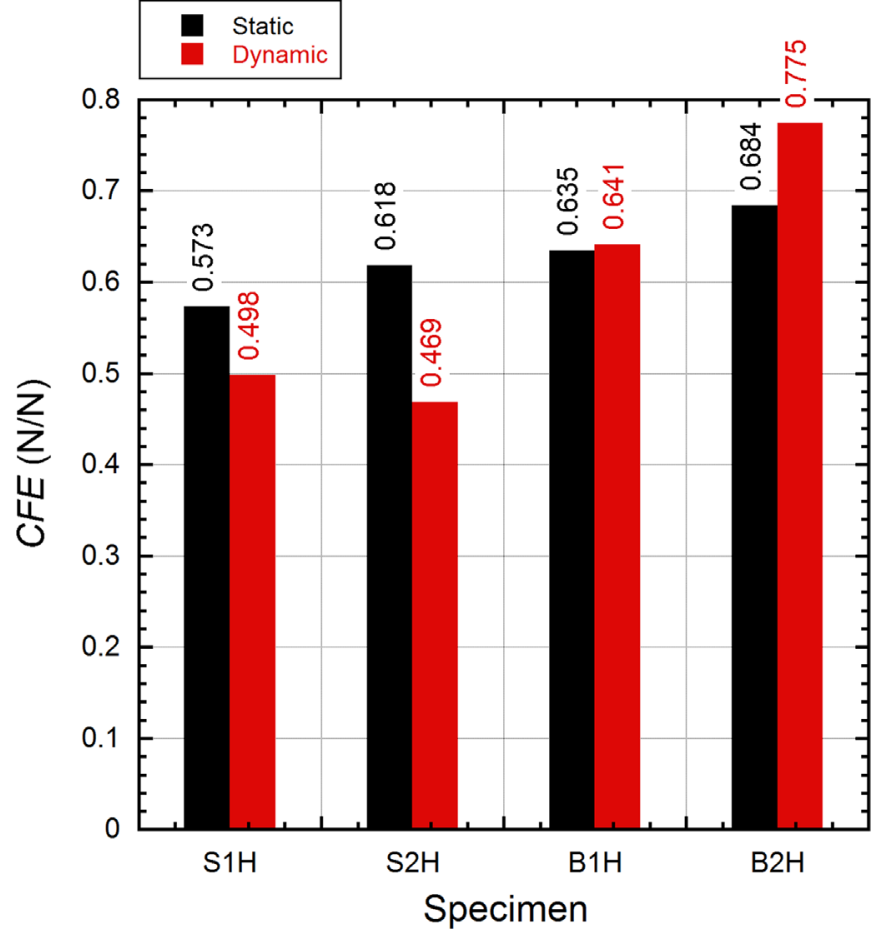

Fig. 8. Static and dynamic CFE.

those of the experiments even though the results are within an acceptable error level. Peak loads are overestimated for B11H specimen (Fig. 6a) and this is the case for mean crush load as well. In the simulation of $\mathrm{B} 22 \mathrm{H}$ (Fig. 6c), deformation mode is successfully captured; on the other hand numerical peak loads are slightly underestimated. The peak forces for crushing of constituents calculated higher and deformation values at peak forces is slightly underestimated in S12H specimen (Fig. 6b). Dadrasi [36] reported the similar differences between experimental and numerical force values in the presence of imperfections. Both static and dynamic numerical models of crushing sequences of B11H and B12H specimens shown sequentially in Fig. $7 \mathrm{a}$ and $\mathrm{b}$ represent well agreements with experimental crushing sequences.

The experimental and numerical quasi-static and dynamic crushing force, energy absorption and compression displacement values of heat-treated combined geometry shells are tabulated in Table 2 . In this table, $P_{i}, P_{\max }$ and $P_{m}$ refer to the initial peak force, maximum force and mean force. The experimental initial peak force of $\mathrm{B} 22 \mathrm{H}$ specimen is $26.54 \mathrm{kN}$, which is $14 \%$ greater than that of quasi-static test $(22.8 \mathrm{kN})$. This initial peak force is also the global maximum force and observed in the buckling of hemispherical portion. This is followed by a load-drop and the rest of the force-displacement curve corresponds to the buckling of cylindrical portion. The highest experimental $P_{\max }$ is observed in $\mathrm{S} 22 \mathrm{H}(33.6 \mathrm{kN})$, which absorbs the highest energy.

Among all the specimens tested, the highest experimental $P_{i}$ value is found in $\mathrm{B} 22 \mathrm{H}$ ( $\mathrm{S} 21$ for as-received alternatives), whereas the lowest $P_{i}$ value in $\mathrm{S} 11 \mathrm{H}$ (S11 for as-received alternatives). The highest experimental $P_{\max }$ value is attained in S22H (B22 for asreceived alternatives), whereas the lowest $P_{\max }$ value in S11H (S11 for as-received alternatives). In order to obtain better crushing performance in this type of structures, maximum load transmitted to the structure should be minimized and the mean load value should be maximized to increase energy absorption capacity. For this purpose, crushing force efficiency (CFE) parameter is calculated using the following relation,

$C F E=\frac{P_{m}}{P_{\max }}$

The calculated experimental CFE values of quasi-statically and dynamically tested heat-treated shells are summarized in Fig. 8. As shown in the same figure, CFE values vary between 0.46 and 0.77 and $\mathrm{B} 22 \mathrm{H}$ specimen shows the maximum, while $\mathrm{S} 22 \mathrm{H}$ specimen shows the minimum dynamic CFE values. Results reveal that for smaller diameter specimens, as loading rate increases CFE decreases, while for bigger diameter specimens as loading rate increases CFE increases as well.

In Fig. 9a and b, the mean crush loads and $S A E$ values of heattreated and as-received specimens are shown, respectively. In the SAE calculations, the experimental results were divided by the measured weight while numerical model results were divided by the numerically determined weights. As seen in the Fig. 9a and b, heat-treatment results in a decrease in the mean crush load and consecutively lower $S A E$ values (Fig. 9b) are found in heat-treated specimens even with longer crushing stroke. As radius and thickness increase in heat-treated specimens, a higher mean crush load is observed in dynamically loaded specimens than statically loaded ones. For the specimens having the same thickness, as the radius increases the mean crush load increases but SAE decreases, the same as the as-received specimens. For the specimens of the same radius, increase in thickness results in increase in both mean crush load and $S A E$ values. For all of the specimens, as loading-rate increases $S A E$ values increase. Interestingly this is again vice versa 
a

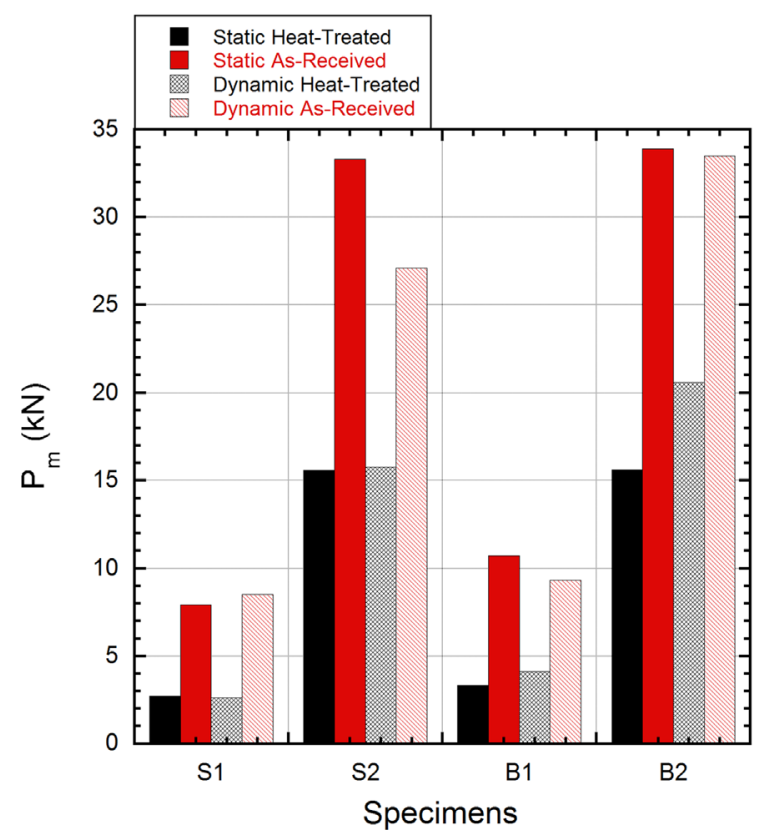

b

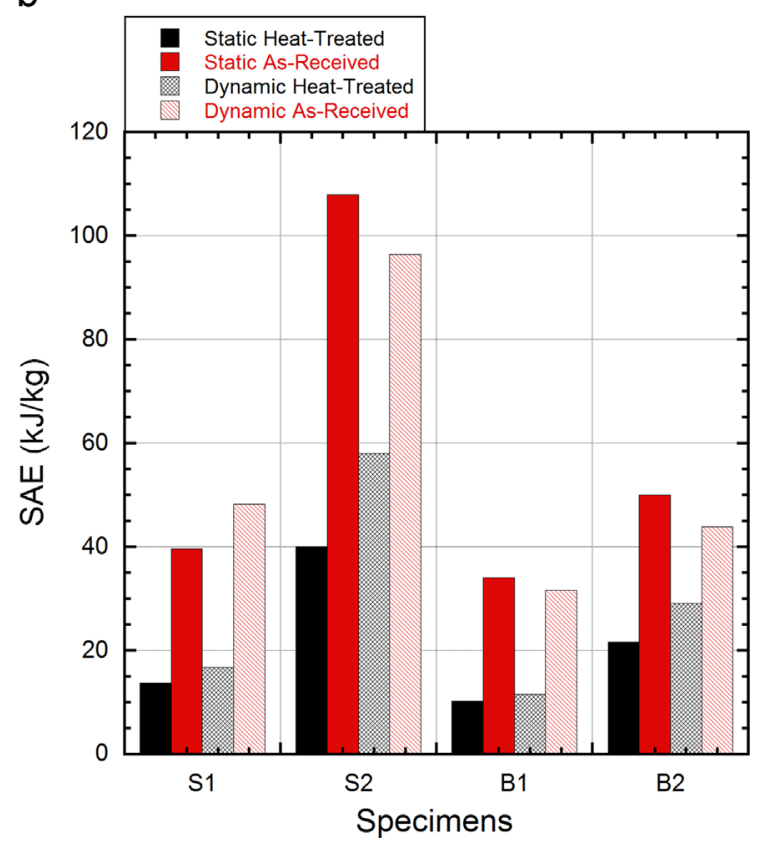

Fig. 9. Comparison of (a) mean load and (b) $S A E$ for heat-treated and as-received specimens.

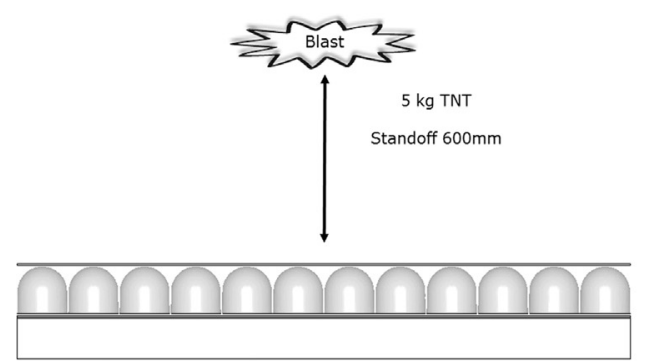

(a)

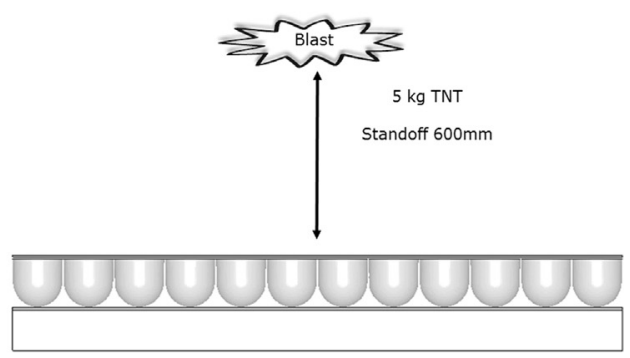

(b)

Fig. 10. Blast loading on (a) forward and (b) reverse sandwiches.

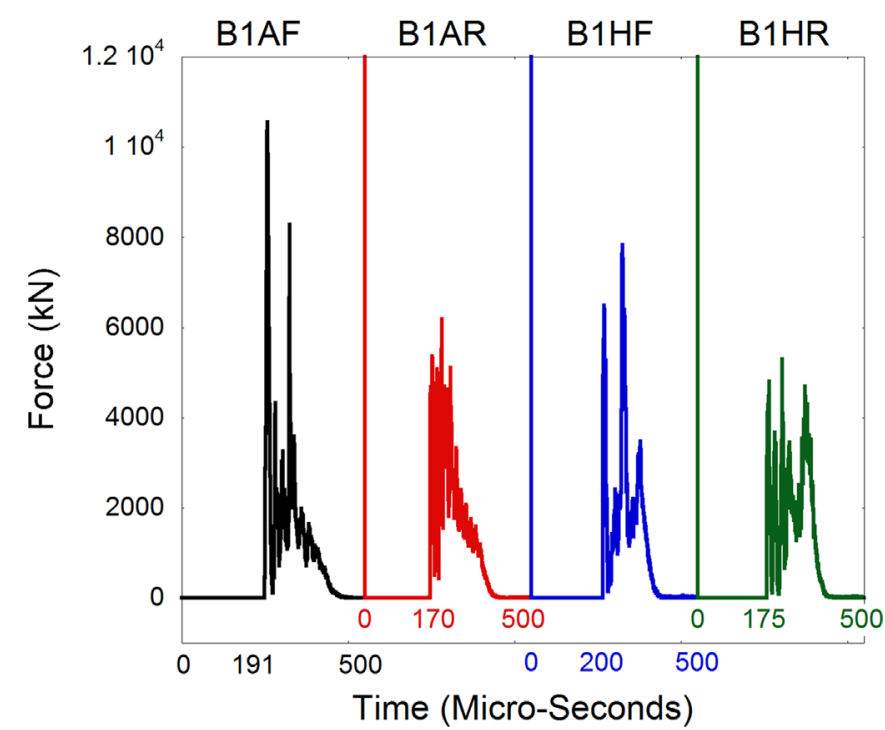

Fig. 11. Transmitted force-time histories for different sandwich configurations.

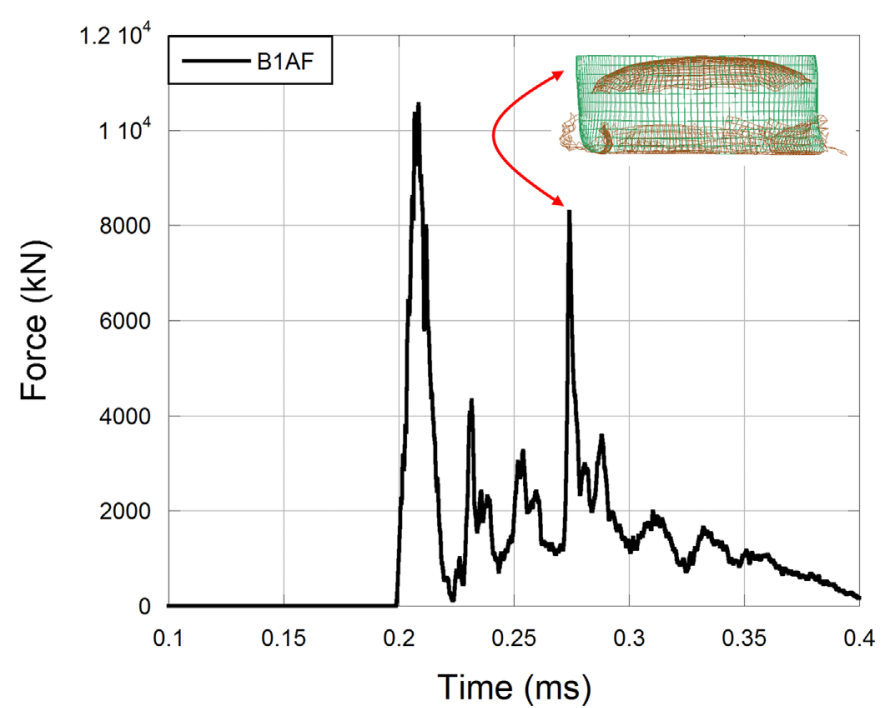

Fig. 12. Formation of subsequent high transmitted peak force. 

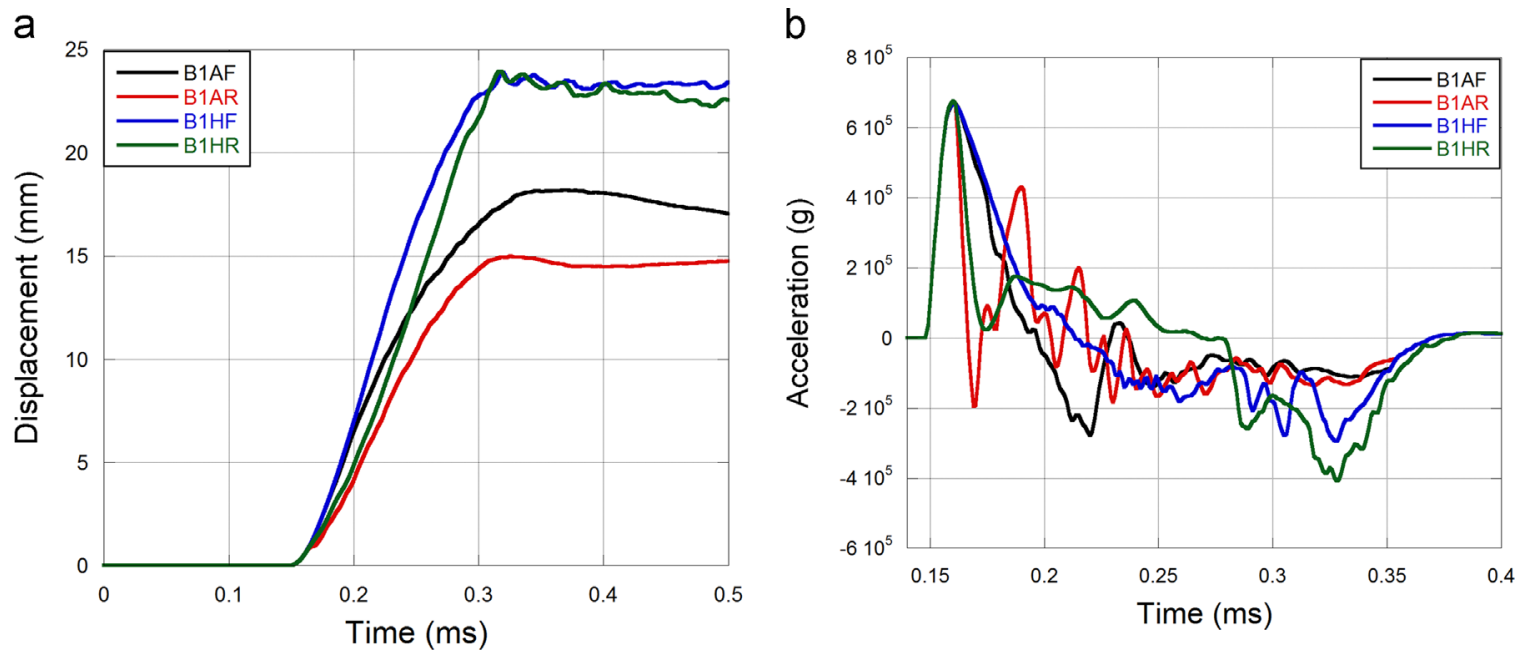

Fig. 13. (a) Displacement-time and (b) acceleration-time histories for front face sheets of different sandwiches.

a

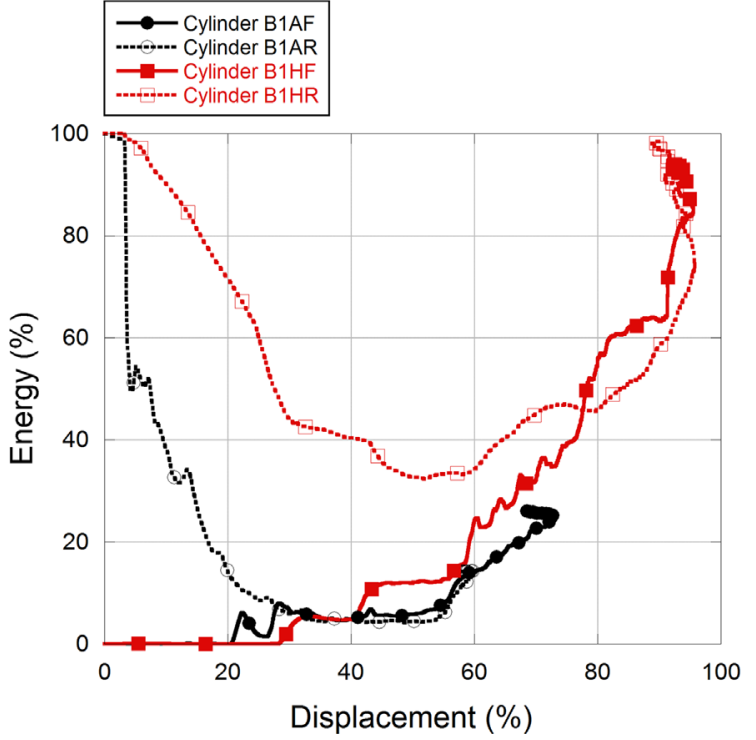

b

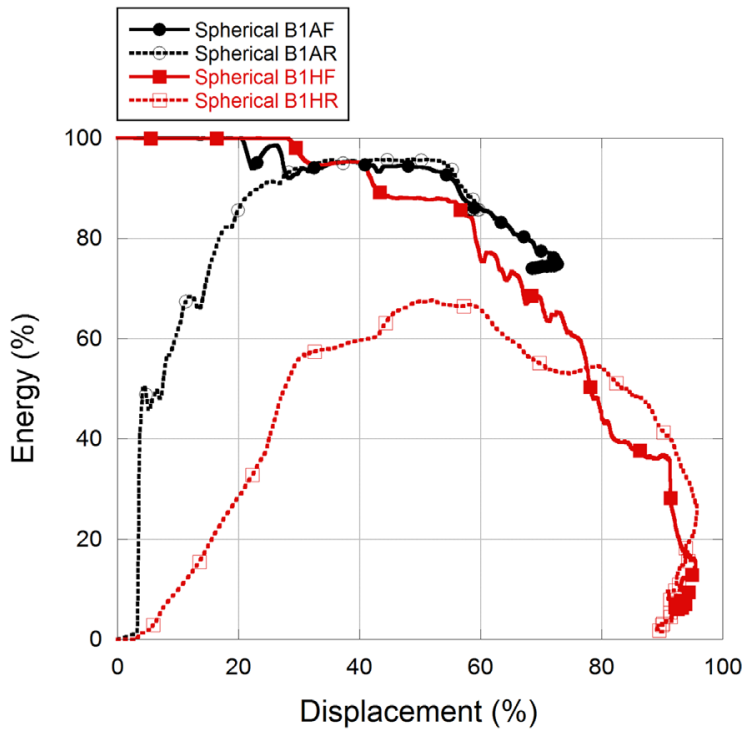

Fig. 14. Energy partitions of as-received and heat-treated unit cores between (a) cylinder (b) hemisphere segments.

Table 3

Results obtained from blast simulations.

\begin{tabular}{|c|c|c|c|c|c|c|}
\hline Specimen & $\begin{array}{l}\text { Initial peak force } \\
(\mathbf{k N})\end{array}$ & $\begin{array}{l}\text { Average force } \\
(\mathbf{k N})\end{array}$ & $\begin{array}{l}\text { Total core compression } \\
(\mathrm{mm})\end{array}$ & $\begin{array}{l}\text { Absorbed energy by sand- } \\
\text { wich }(\mathrm{J})\end{array}$ & $\begin{array}{l}\text { SAE of sandwich } \\
(\mathrm{kJ} / \mathrm{kg})\end{array}$ & $\begin{array}{l}\text { Average front face velo- } \\
\text { city }(\mathrm{m} / \mathrm{s})\end{array}$ \\
\hline $\mathrm{B} 1 \mathrm{AF}$ & 10555 & 1602 & 18.000 & 24194 & 30.610 & 184 \\
\hline B1HF & 6491 & 1926 & 23.790 & 11516 & 14.540 & 232 \\
\hline $\mathrm{B} 2 \mathrm{AF}$ & 13946 & 3798 & 7.020 & 19077 & 11.530 & 139 \\
\hline $\mathrm{B} 2 \mathrm{HF}$ & 7234 & 1825 & 10.820 & 23791 & 14.460 & 152 \\
\hline S1AF & 9362 & 2026 & 6.800 & 16979 & 22.810 & 127 \\
\hline S1HF & 5855 & 3167 & 12.870 & 10832 & 14.430 & 188 \\
\hline S2AF & 15461 & 2046 & 2.820 & 9320 & 6.310 & 89 \\
\hline $\mathrm{S} 2 \mathrm{HF}$ & 10847 & 1570 & 5.360 & 16523 & 11.230 & 112 \\
\hline B1AR & 4637 & 1845 & 14.980 & 22110 & 28.000 & 166 \\
\hline B1HR & 4100 & 1865 & 23.930 & 13993 & 17.676 & 208 \\
\hline B2AR & 5718 & 2833 & 6.060 & 12926 & 7.830 & 115 \\
\hline B2HR & 4345 & 2382 & 9.736 & 16342 & 9.869 & 105 \\
\hline S1AR & 5516 & 1821 & 6.820 & 14624 & 19.460 & 117 \\
\hline S1HR & 4346 & 2709 & 13.154 & 10660 & 14.240 & 136 \\
\hline S2AR & 7312 & 4342 & 2.580 & 7422 & 5.030 & 71 \\
\hline S2HR & 4473 & 3105 & 4.719 & 12134 & 8.220 & 74 \\
\hline
\end{tabular}




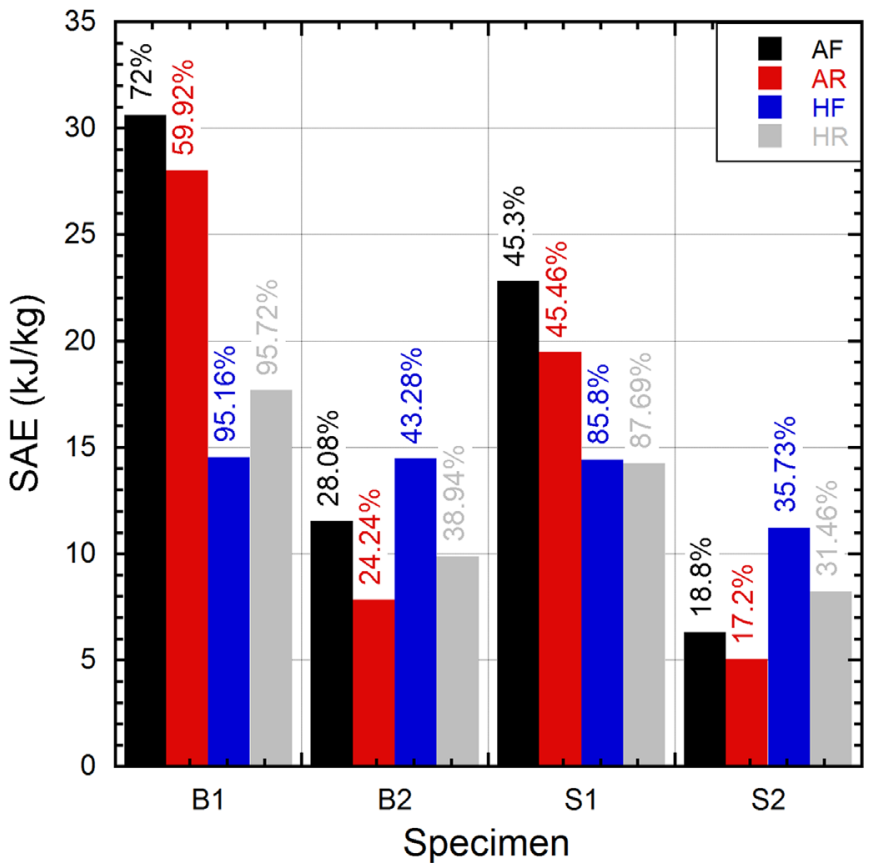

Fig. 15. $S A E$ of blast loaded sandwiches (added values show core compression \%).

in as-received S2, B1, and B2 specimens as in the case of CFE.

\subsection{Blast simulations}

The blast response of sandwiches consisting of as-received and heat-treated combined geometries were determined for forward and reversed configurations as shown in Fig. 10(a) and (b), respectively. The history of transmitted forces to the protected structure, which is one of the most important design factor for blast protection, are shown together in Fig. 11 for the studied sandwich configurations. Each curve in Fig. 11 is drawn with its own horizontal time axis to clarify the time delay. As can be seen in the figure, the highest transmitted peak force is seen in the $\mathrm{B} 1 \mathrm{AF}$ and the lowest in B1HR. It is apparent from figure that reversing core units decreases transmitted peak force for both asreceived and heat-treated configurations. The heat-treatment results in further decrease in transmitted force. The maximum amount of time delay is found in B1HF, while the minimum in $\mathrm{B} 1 \mathrm{AR}$. The reversing results in a decrease in arrival time and on the other hand heat-treatment increases the arrival time of force wave to the protected structure. As suggested in the literature [36] strain hardening properties of materials affects the plastic deformations. Lower values of the strain hardening modulus result in lower plastic wave speed. Due to manufacturing effects, plastic strain induced on cylindrical portion of the studied shell is lower than that of spherical portion and strain hardening modulus of cylindrical portion is higher. Hence, stress wave travels through shells more rapidly when the cylindrical portion is in the impact face. Stress wave traveled through B1AF sandwich in $35 \mu \mathrm{s}$, B1HF sandwich in $45 \mu \mathrm{s}$, B1AR sandwich in $9 \mu \mathrm{s}$, and B1HR sandwich in $14 \mu \mathrm{s}$. As the strain hardening modulus of heat-treated material is lower than that of as-received material, time delay is higher in heat-treated sandwich configurations. Throughout the deformation process, the contact surface of cylindrical portion is always higher than contact surface of hemispherical portion. Therefore, wave speed within the material is lower in cylindrical portion: then in reversed cases wave hits protected structure earlier than forward cases.

In order to have a better understanding of the deformation process in $\mathrm{B} 1 \mathrm{AF}$, a detailed transmitted force-time history is given with a deformed view of the specimen in Fig. 12. As can be seen, the first peak is followed by two low-level peak forces and then a relatively higher third peak load is observed in the curve. As observed from the numerical simulations, after the plastic deformation the deformed hemi-spherical cap of the core structure is separated from the specimen body and hit onto the back face of the sandwich and induces a relatively high peak force. In reversed configurations, this was not encountered.

In Fig. 13a and b, the displacement-time and acceleration-time histories for front face sheets of four different sandwiches are shown, respectively. Heat-treated core containing sandwiches show higher deformations than those of as-received ones. Reversing shows no significant change in the deformation history in heat-treated configurations, while for as-received configurations slight decrease in deformation values are calculated. This may be due to the fact that the contact surface of reversed configurations are greater than those of forward one's and this results in lower front face velocities. Thus, the final deformation of B1AR configuration is lower than B1AF. As seen in Fig. 13b, peak accelerations for all configurations are similar due to the application of the same blast charge on front face sheets. However, the rest of the curves corresponding to the deceleration behavior are slightly different due to the difference in geometrical and material properties of different core structures. In the B1AR configuration high successive peaks are visible. On the other hand, for the rest of the configurations a constantly decreasing behavior is observed after the first peak. These different behaviors may arise as a result of different boundary conditions at the front face sheets due to geometrical and material differences. As a result of higher negative accelerations observed in heat-treated cases at the later stages of the blast event, a steeper descending behavior is observed in the force-time histories given in Fig. 11.

In Fig. 14a and b, the energy partitions of unit core components (cylindrical and hemi-spherical segments) are shown for heattreated and as-received sandwiches, respectively. The location of the investigated unit core is in the middle of the structure. As can be seen from the figure forward and reversed placement of unit cores significantly alter the energy partitioning, namely in forward configurations, most of the initial load is carried by the hemispherical cap in the beginning of deformation. In B1AF, configuration up to $20 \%$ of deformation almost all of the energy absorbed by hemi-spherical cap and this value is almost extended to $30 \%$ of deformation in the heat-treated B1HF configuration (Fig. 14a and b). However, for reversed configurations such as B1AR both components of unit core immediately start carrying load and this clearly explains the decrease of time delay in the force history data. As the deformation progresses energy absorbed by hemispherical cap continuously increases, while for cylindrical segment continuously decreases. When heat treatment and reversing effects considered together i.e. B1HR configuration, cylindrical segment absorbed more energy initially until about $25 \%$ deformation, then energy sharing become equal and hemi-spherical segment absorbed much of the energy through the rest of the deformation. For the reversed configurations, heat treatment causes closer energy sharing ratios than those of as-received; this may be attributed to different deformation characteristics as will be explained later.

The results of blast simulations are summarized in Table 3 . The maximum transmitted initial peak force is found in S2AF configuration and the lowest in B1HR. The highest average force is calculated for S2AR sandwich and the lowest for S2HF. For the specimens having the same radius, lower initial peak forces is calculated for heat-treated configurations than those of as-received. In addition, reversing results in further reduction in the initial peak force values. As the total core compression is considered, the 
a

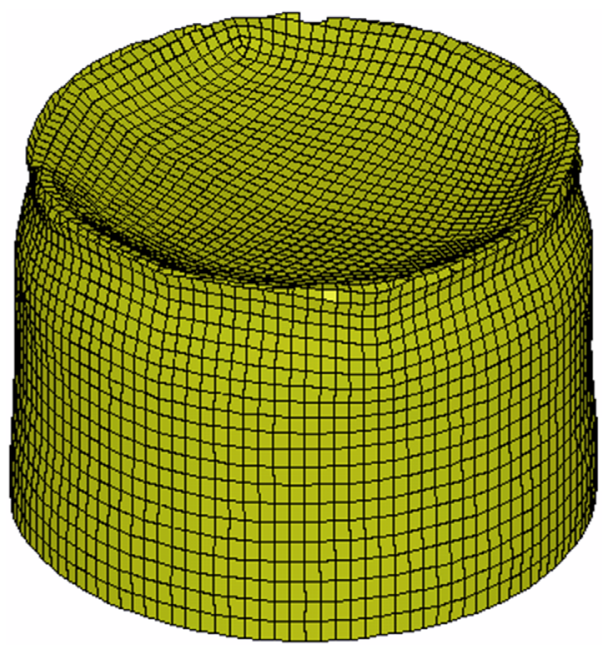

C

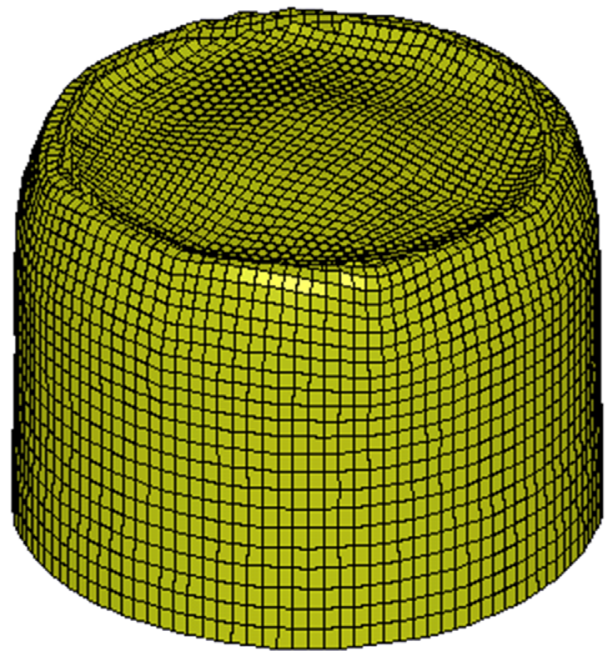

b

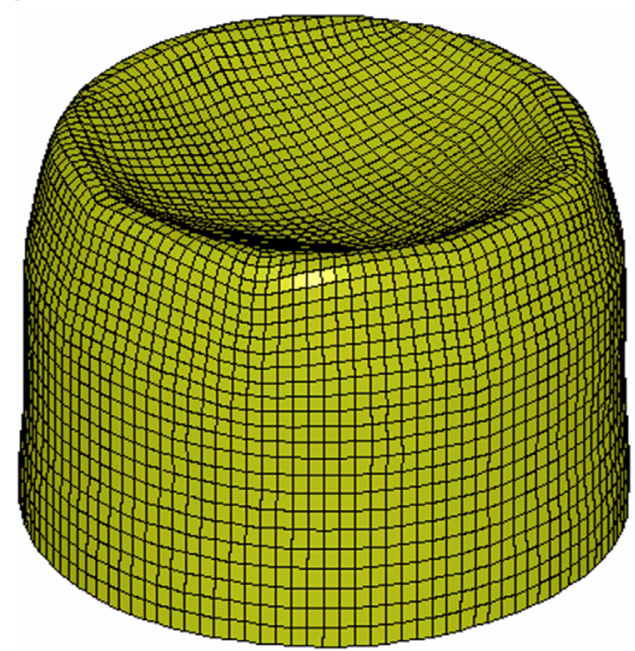

d

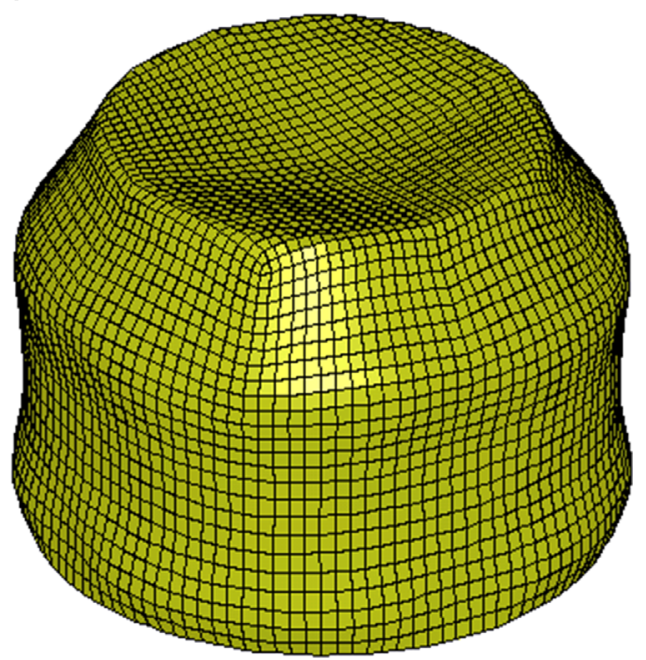

Fig. 16. Deformed views of middle core units at $\sim 6 \mathrm{~mm}$ deformation; (a) B1AF, (b) B1AR, (c) B1HF, (d) B1HR.

lowest value is calculated for S2AR, which reasonably results in relatively high peak transmitted forces as previously reported. While, the highest amount of total core compression is calculated for B1HR configuration and the lowest transmitted force is noted.

In terms of energy absorption and blast protection efficiency, total core compression is a vital parameter. Depending on the threat, different types of geometrical configurations and different material (heat treated or not) types can be used. During the service time of the configuration, the amount of core compression should be kept below the fully densification region. However, significantly lower core compression values are also not desired due to the relatively lower SAE values. Due to the higher flow stress levels for as-received core units, buckling loads to be overcome are significantly higher, so corresponding absorbed energy levels are higher. Accordingly, the lowest SAE is calculated for S2AR configuration owing to the lower core compression and the highest is calculated for B1AF sandwich due to the relatively higher amount of deformation and relatively lower weight. The average front face velocities are also summarized in Table 3 . It is noted that in the calculation of SAE, the face plate weight was not taken into account since the main motivation in current study was to investigate the energy absorption efficiency of different core geometries. For a deformed sandwich, this can be a measure of deformation rate throughout the crushing. The highest value is calculated for B1HR sandwich, which also has the highest amount of deformation. The lowest average front face velocity is obtained in the configuration of S2AR and which also has the lowest total core compression. In reverse configurations, average front face velocities are lower than those of forward. The initial momentum is transferred to the cylindrical portion first in reversed cases. For forward configurations, absorbed energies are calculated higher than those of reversed and that might be related to the lower strain rates resulting from the lower front face velocities obtained in reversed cases.

The effects of heat-treatment and reversing on $S A E$ with corresponding core compression percentages are shown in Fig. 15. Reversing causes decrease in SAE for all as-received configurations, which is also valid for the most heat-treated configurations but for B1HF and B2HR. Apparently, heat treatment results in decrease in $S A E$ for thinner specimens. As radius decreases $S A E$ also decreases for all of the configurations. As thickness increases, $S A E$ again decreases due to less amount of deformation obtained. Energy absorption effectiveness of heat treated forward B1HF, B2HF, and S2HF configurations are almost equal.

In Fig. 16 deformed views of unit core structures placed in the middle of different configurations are shown for $\sim 6 \mathrm{~mm}$ of front face displacement. As seen in figure, for B1AF case fracture immediately initiates at the hemispherical portion before detection of 
a fully formed plastic hinge. On the other hand, when reversed, plastic hinge formation is observed, Fig. 16b. These are also valid for heat-treated specimens except for a deformation mode change of reversed heat-treated specimen. For heat-treated cases, reversing results in a global buckling in cylindrical segment along with the flattening behavior of hemispherical portion. This reversing related mode change results in higher energy absorption and consequently higher SAE values. As shown in Fig. 14, energy percentages of components of B1AR unit core become equal to $50 \%$ immediately after the beginning of deformation. On the other hand due to the operative deformation mode change in B1HR case, energy percentages cannot reach $50 \%$ until almost $25 \%$ of deformation.

\section{Conclusions}

The effect of heat treatment on the energy absorption characteristics and crushing behavior of combined geometry shells at quasi-static and high strain rates were investigated both experimentally and numerically. The applied heat treatment resulted in relief of residual stresses caused by manufacturing process, thus lowering crushing force values. Numerical models of both quasistatic and low velocity crushing tests showed good correlation with experimental results in force-displacement curves and deformation behavior. Differences in peak loads of some numerical cases were attributed to the imperfections. The highest value of crushing force efficiency was found in $\mathrm{B} 22 \mathrm{H}$ structure and the lowest in S22H. The increase in loading rate resulted in decrease in CFE value of smaller radius specimens and increase in CFE value of larger radius specimens. When thickness was kept constant, CFE values increased as radius increased for both loading rates. Heat treatment resulted in a negative effect on SAE values due to decrease in mean crushing force. When thickness was kept constant and as radius increased, mean crushing load increased while the specific absorbed energy decreased. Numerical blast studies showed that reversing core units resulted in decrease in transmitted force for both as-received and heat treated configurations. Besides, some amount of decrease for transmitted force values were observed due to heat treatment. Reversing of core units resulted in a decrease in arrival time and heat treatment increased the arrival time of force wave to the protected structure. After the plastic deformation, fractured hemi-spherical cap of core structures split from the specimen body and impacted onto the back face of sandwich thus induced a relatively high peak force. This phenomenon was not encountered in reversed cases (hemispherical part was at the impacted side). Reversing in heat treated configurations showed no significant change in the deformation history. On the other hand, in as-received configurations, reversing resulted in decrease in deformation values. The highest and lowest average force values were in S2AR and S2HF sandwich configurations, respectively. The lowest total core compression was in S2AR which logically resulted in relatively high peak transmitted forces. Reversely, B1HR configuration has the highest amount of total core compression and which resulted in lowest transmitted force. Reversing resulted in decrease in SAE for all as-received cases. For B1AF case fracture immediately initiates at hemispherical portion before detection of a fully formed plastic hinge. On the other hand, when unit cores reversed plastic hinge formed. These were also valid for heat-treated specimens except for a mode change when heat-treated specimens reversed.

\section{Acknowledgment}

The authors would like to thank the Scientific and Technical Council of Turkey (TUBITAK) for the Grant \# 112M141.

\section{References}

1] N.K. Gupta, N. Mohamed Sheriff, R. Velmurugan, Analysis of collapse behaviour of combined geometry metallic shells under axial impact, Int. J. Impact Eng. 35 (2008) 731-741.

[2] N.K. Gupta, N.M. Sheriff, R. Velmurugan, A study on buckling of thin conical frusta under axial loads, Thin-Walled Struct. 44 (2006) 986-996.

[3] A. Niknejad, A. Tavassolimanesh, Axial compression of the empty capped-end frusta during the inversion progress, Mater. Des. 49 (2013) 65-75.

[4] P.K. Gupta, A study on mode of collapse of varying wall thickness metallic frusta subjected to axial compression, Thin-Walled Struct. 46 (2008) 561-571.

[5] P.K. Gupta, Axial compression of tubular metallic shells having combined tubefrusta geometry, International Conference on Structural Engineering Construction and Management (ICSECM-2011), Sri Lanka, 2011.

[6] P.K. Gupta, N.K. Gupta, A study on axial compression of tubular metallic shells having combined tube-cone geometry, Thin-Walled Struct. 62 (2013) 85-95.

[7] A. Ghamarian, M.T. Abadi, Axial crushing analysis of end-capped circular tubes, Thin-Walled Struct. 49 (2011) 743-752.

[8] A. Ghamarian, H.R. Zarei, M.T. Abadi, Experimental and numerical crashworthiness investigation of empty and foam-filled end-capped conical tubes, Thin-Walled Struct. 49 (2011) 1312-1319.

[9] A. Ghamarian, H. Zarei, Crashworthiness investigation of conical and cylindrical endcapped tubes under quasi-static crash loading, Int. J. Crashworthines 17 (2012) 19-28.

[10] A. Ghamarian, H.R. Zarei, M.A. Farsi, N. Ariaeifar, Experimental and numerical crashworthiness investigation of the empty and foam-filled conical tube with shallow spherical caps, Strain 49 (2013) 199-211.

[11] M.H. Shojaeefard, A. Najibi, M. Anbarloei, M. Yeganeh, Experimental and numerical crashworthiness investigation of combined circular and square sections, J. Mech. Sci. Technol. 28 (2014) 999-1006.

[12] V. Jandaghi Shahi, J. Marzbanrad, Analytical and experimental studies on quasistatic axial crush behavior of thin-walled tailor-made aluminum tubes, Thin-Walled Struct. 60 (2012) 24-37.

[13] R. Sahu, P. Gupta, Geometrical metallic shell behavior study under compression, Int. J. Adv. Struct. Eng. 5 (2013) 1-12.

[14] N.K. Gupta, S.K. Gupta, Effect of annealing, size and cut-outs on axial collapse be haviour of circular tubes, Int. J. Mech. Sci. 35 (1993) 597-613.

[15] N.K. Gupta, Some aspects of axial collapse of cylindrical thin-walled tubes, ThinWalled Struct. 32 (1998) 111-126.

[16] P.K. Gupta, N.K. Gupta, A study of different modes of collapse in metallic hemispherical shells resting on flat platen and compressed with hemispherical nosed indenter, Int. J. Solids Struct. 51 (2014) 2518-2528.

[17] W. Li, G. Huang, Y. Bai, Y. Dong, S. Feng, Dynamic response of spherical sandwich shells with metallic foam core under external air blast loading - numerical simulation, Compos. Struct. 116 (2014) 612-625.

[18] X.R. Liu, X.G. Tian, T.J. Lu, B. Liang, Sandwich plates with functionally graded metallic foam cores subjected to air blast loading, Int. J. Mech. Sci. 84 (2014) 61-72.

[19] F. Zhu, L. Zhao, G. Lu, Z. Wang, Deformation and failure of blast-loaded metallic sandwich panels-experimental investigations, Int. J. Impact Eng. 35 (2008) 937-951.

[20] G.N. Nurick, G.S. Langdon, Y. Chi, N. Jacob, Behaviour of sandwich panels subjected to intense air blast - Part 1: experiments, Compos. Struct. 91 (2009) 433-441.

[21] Y Chi, G.S. Langdon, G.N. Nurick, The influence of core height and face plate thickness on the response of honeycomb sandwich panels subjected to blast loading, Mater. Des. 31 (2010) 1887-1899.

[22] X. Li, Z. Wang, F. Zhu, G. Wu, L. Zhao, Response of aluminium corrugated sandwich panels under air blast loadings: Experiment and numerical simulation, Int. J. Impact Eng. 65 (2014) 79-88.

[23] M. Yazici, J. Wright, D. Bertin, A. Shukla, Experimental and numerical study of foam filled corrugated core steel sandwich structures subjected to blast loading, Compos. Struct. 110 (2014) 98-109.

[24] R. Alberdi, J. Przywara, K. Khandelwal, Performance evaluation of sandwich panel systems for blast mitigation, Eng. Struct. 56 (2013) 2119-2130.

[25] G. Randers-Pehrson, K.A. Bannister, ARL-TR-1310: Airblast Loading Model for DYNA2D and DYNA3D, Army Research Laboratory, 1997.

[26] LSTC, LS-DYNA: Keyword User's Manual, Livermore Software Technology Corporation, in, LSTC, 2007.

[27] S. Palanivelu, W. Van Paepegem, J. Degrieck, S. De Pauw, J. Vantomme, J. Wastiels, D. Kakogiannis, D. Van Hemelrijck, Low velocity axial impact crushing performance of empty recyclable metal beverage cans, Int. J. Impact Eng. 38 (2011) 622-636.

[28] S. Palanivelu, W. Van Paepegem, J. Degrieck, B. Reymen, J.-M. Ndambi, J. Vantomme D. Kakogiannis, J. Wastiels, D. Van Hemelrijck, Close-range blast loading on empty recyclable metal beverage cans for use in sacrificial cladding structure, Eng. Struct. 33 (2011) 1966-1987.

[29] A. Tasdemirci, S. Sahin, A. Kara, K. Turan, Crushing and energy absorption characteristics of combined geometry shells at quasi-static and dynamic strain rates: Experimental and numerical study, Thin-Walled Struct. 86 (2015) 83-93.

[30] A. Tasdemirci, A. Kara, K. Turan, S. Sahin, Dynamic crushing and energy absorption of sandwich structures with combined geometry shell cores, Thin-Walled Struct. 91 (2015) $116-128$

[31] S. Weber, M. Martin, W. Theisen, Impact of heat treatment on the mechanical properties of AISI 304L austenitic stainless steel in high-pressure hydrogen gas, J. Mater. Sci. 47 (2012) 6095-6107.

[32] S.P. Santosa, T. Wierzbicki, A.G. Hanssen, M. Langseth, Experimental and numerical studies of foam-filled sections, Int. J. Impact Eng. 24 (2000) 509-534.

[33] Z. Maker, A Procedure for Springback Analysis Using LS-DYNA.

[34] P.D. Smith and J.G. Hetherington, Blast and Ballistic Loading of Structures, Oxford; Boston: Butterworth-Heinemann, 1994.

[35] F. Zhu, G. Lu, A review of blast and impact of metallic and sandwich structures, Electron. J. Struct. Eng. (2007) 92-101.

[36] A. Dadrasi, Energy absorption of semi-spherical shells under axial loading, Aust. ]. Basic Appl. Sci. 5 (2011) 2052-2058. 